\title{
Prey predator interactions in the face of management regulations: changes in Mediterranean small pelagics are not due to increased tuna predation
}

\author{
Van Beveren Elisabeth ${ }^{1,{ }^{*}}$, Fromentin Jean-Marc ${ }^{1}$, Bonhommeau Sylvain ${ }^{1,4}$, Nieblas Anne-Elise ${ }^{1}$, \\ Metral Luisa ${ }^{1}$, Brisset Blandine ${ }^{1}$, Jusup Marko ${ }^{2}$, Bauer Robert Klaus ${ }^{1}$, Brosset Pablo ${ }^{1,3}$, \\ Saraux Claire ${ }^{1}$
}

\footnotetext{
${ }^{1}$ IFREMER (Institut Français de Recherche pour l'Exploitation de la MER), UMR MARBEC, Avenue Jean Monnet, BP171, 34203 Sète Cedex France

${ }^{2}$ Center of Mathematics for Social Creativity, Hokkaido University, N12 W7 Kita-ku, 060-0812 Sapporo, Japan

${ }^{3}$ Université Montpellier II, UMR MARBEC, Avenue Jean Monnet, BP171, 34203 Sète cedex, France

${ }^{4}$ IFREMER Délégation de I'Océan Indien, Rue Jean Bertho, BP60, 97822 Le Port CEDEX France

* Corresponding author : Elisabeth Van Beveren, email address : elisvb@hotmail.com
}

\begin{abstract}
:
Recently, the abundance of young Atlantic bluefin tuna ( Thunnus thynnus) tripled in the North-western Mediterranean following effective management measures. We investigated whether its predation on sardine ( Sardina pilchardus) and anchovy ( Engraulis encrasicolus) could explain their concurrent size and biomass decline, which caused a fishery crisis. Combining the observed diet composition of bluefin tuna, their modelled daily energy requirements, their population size and the abundance of prey species in the area, we calculated the proportion of the prey populations that were consumed by bluefin tuna annually over 2011-2013. To assess whether tuna could alter the size structure of the three small pelagic populations (anchovy, sardine and sprat), the size distributions of the consumed prey species were compared to those of the wild populations. We estimated that the annual consumption of small pelagic fish by bluefin tuna is less than $2 \%$ of the abundance of these populations. Furthermore, size selectivity patterns were not observed. We thus concluded that tuna predation is unlikely to be the main cause of major changes in the small pelagic fish populations from this area.
\end{abstract}



Introduction

Understanding predator-prey relationships is crucial for ecosystem-based management. One of the key aspects of these relationships concerns estimates of predation strength, which can be affected by conservation measures (Bailey et al. 2010). Assessing predation pressure is a data intensive issue (Essington et al. 2001) and direct information at the population level is difficult to obtain for marine systems due to the practical constraints and high costs of observing marine species (but see e.g. Mann and Lazier 2005 for examples). Estimates are generally based on the predator population abundance, energy requirements and prey composition, as well as the population abundance and energetic value of the prey. Estimates of food requirements are particularly problematic due to the limitations of the existing methods. Also, predation might influence aspects of the prey population structure or dynamics, such as the size distribution.

Since 2007, significant changes have been observed in the small pelagic populations of the Gulf of Lions in the north-western Mediterranean Sea. Size and condition of sardine (Sardina pilchardus) and anchovy (Engraulis encrasicolus) have significantly decreased, resulting in important economic losses for fisheries (Van Beveren et al. 2014, Brosset et al. 2015). Notably, sardine captures even slumped to a 150 years low (Van Beveren et al. 2016a). Also, the biomass of both populations stayed at an intermediate level for an extended period, which is rather remarkable for these usually highly fluctuating populations (see supplementary files Fig. S1 for abundance and biomass time series). Nonetheless, abundance was high due to high recruitment (especially for sardine), so that the ratio biomass/abundance strongly decreased. In contrast, sprat (Sprattus sprattus), a species with no commercial value in this area, has shown a remarkable upsurge (GFCM 2011). Several hypotheses have been suggested as potential drivers for these changes, including changes in planktonic quantity and/or quality (i.e. a bottom-up control), predation (i.e. a top-down-control) and an epizootic disease (Van Beveren et al. 2014, 2016b, Brosset et al. 2015, 2016). These are not exclusive, but potentially 
acting in synergy (Planque et al. 2010). For example, top-down controlling factors could result in a truncation of the size distribution and impede populations from rebuilding.

In the present study, we investigated the potential impacts of top-down control, with the aim of obtaining the most comprehensive insight in the pelagic ecosystem changes. As fishing is an unlikely driver due to low exploitation rates of these populations (see Van Beveren et al. 2016), we consider the potential impacts of natural predation due to the main predator of small pelagic fish in the area, i.e. Atlantic bluefin tuna (Fromentin and Powers 2005).

Atlantic bluefin tuna (ABFT, Thunnus thynnus) predates on a variety of prey, among which small pelagic fish, such as in the Northwest, central and east Mediterranean Sea, the Bay of Biscay and the Northeast and Northwest Atlantic (see Fromentin and Powers 2005a for a review). Juveniles and young adults may reside many months in the Gulf of Lions to feed on sardine, anchovy and sprat (Fromentin and Lopuszanski 2014). Other top predators are also present (marine mammals, predatory fish, sharks, seabirds and marine turtles) but their impact is estimated to be of lesser importance, as they prey mostly on other species (e.g. dolphins, David and Di-Méglio 2013), consume small pelagics only for a limited period of the year, are geographically restricted (such as some birds to the surface and some marine mammals to deeper waters, Praca and Gannier 2008), and/or do have significantly smaller populations than tuna (e.g. dolphins, Bauer et al. 2015b). Furthermore, ABFT abundance in the Gulf of Lions has been much higher in recent years (Bauer et al. 2015). This is probably due to the implementation of a recovery plan in 2007 (including fishing season restrictions, quotas and a minimum landing weight of $30 \mathrm{~kg}$ ), which has considerably decreased the fishing pressure on juvenile ABFT in the NW Mediterranean (Fromentin et al. 2014). The increase in juvenile ABFT abundance in this area thus occurred concomitantly with the small pelagic population changes. This leads to the question: could the increase in ABFT abundance, and thus increased predation pressure, have strongly impacted the small pelagic fish populations? Currently, most management 
82

approaches focus on a single species, without considering subsequent impacts on other species in the ecosystem. However, if these management measures have repercussions on other species, management strategies should be adapted accordingly.

Thus, for the Gulf of Lions, which is an important nursery ground for ABFT (Druon et al. 2011), we aimed at investigating the predation pressure exerted by ABFT on sardine, anchovy and sprat from 2011 to 2013 in terms of abundance and size distribution. We addressed three questions; (I) what is the diet composition of ABFT in the area?, (II) what biomass does ABFT remove from this ecosystem and how does this relate to the population size of each prey? and (III) are ABFT prey size selective and could they affect their prey population's size distributions? The tuna diet composition, the annual proportion of each small pelagic population consumed by ABFT and its size selectivity were estimated, using: (a) ABFT population abundance estimates from an ABFT census, (b) a comprehensive bioenergetics model to estimate consumption rates of ABFT, (c) stomach content analyses to define the ABFT diet and (d) the population size and characteristics of each small pelagic species estimated from a small pelagic fish census (Fig. 1). A large predation-associated mortality could completely or partly explain the recently observed changes in the Gulf of Lions ecosystem.

\section{Material and methods}

\section{Estimating predator abundance and weight structure}

Not the whole Atlantic bluefin tuna (ABFT) population was under study, but only the fraction that inhabits permanently or not the Gulf of Lions and is known to be mostly composed of juveniles and young adults (see Fromentin and Powers 2005a). Annual ABFT abundances (2011-2012) were obtained from aerial surveys (Bauer et al. 2015). ABFT school abundances and densities were estimated using strip and line transect approaches from the distance sampling theory (Thomas et al. 2012). Annual abundances (mean $\pm s d$ ) of ABFT in the NW Mediterranean were found to be of $16,2 \pm 4,4.10^{3}$ in 2011 and 12,5 $\pm 3,8.10^{3}$ in 2012 (Supplementary files Fig. S2 and Appendix 1). 
Predation pressure also depends on the residence time of the tuna population in the area, which was estimated based on tag data (Fromentin and Lopuszanski 2014). We considered that ABFT reside in the Gulf of Lions for a total of six months (consistent with previous assumptions, see Bănaru et al. 2013), from approximately early-March to end-May and from end-July until end-October.

Finally, the mass distribution of the tuna population was assessed combining mass values of ABFT sampled for stomach contents with additional measurements of commercially fished ABFT from other periods but caught in the same area (sampling period: generally April-May and July-October of 2011-2014, with 3 individuals in November/December amongst $\mathrm{N}=310$ ). The small scale fishery catches are a good proxy for the ABFT demography (size and age composition) in this area. This is the only fleet targeting ABFT, it operates all year round in this area and the size distribution of its catches corresponds to this of the industrial purse seine fleet that operated in the Gulf of Lions until 2007 (Fromentin 2003). A gamma distribution (shape $=15.21$ and rate $=0.57$ ) was fitted on this empirical histogram, which was also used to determine the ABFT weight range. This information is essential as heavier tuna have a larger energetic requirement.

\section{Estimating ingestion rates of ABFT using a Dynamic Energy Budget model}

A Dynamic Energy Budget (DEB) model describes an individual's energy acquisition (food intake) and use (for e.g. maintenance, growth, reproduction) throughout its life cycle, taking into account external variables, such as temperature and food density (Nisbet et al. 2000, Kooijman 2010). DEBbased modelling is a general and formal approach built on the guiding principle that the mechanisms responsible for running a metabolism apply universally to organisms of all species (Sousa et al. 2008, 2010, Kooijman 2010). We ran a DEB model for ABFT (see Supplementary files Table S2, S3 and Fig. S3) by reparameterising a calibrated and validated model for Pacific Bluefin tuna (Jusup et al. 2011, 2014). For our study, the most important usage of the DEB model is to relate tuna body size to the ingestion rate function (Jusup et al. 2014): 
131 where $p_{A m}$ is the maximum surface-area-specific assimilation rate, $M_{1}$ is the shape correction

132 function (which accounts for morphological changes), $L$ is the structural length and $\kappa_{x}$ is the 133 assimilation efficiency. Food availability $(f)$ and average temperature $(T)$ were assumed to be 0.99 134 and $19.5^{\circ} \mathrm{C}$, respectively ( $T$ is transformed with a temperature correction function to fit with the 135 optimal temperature range of ABFT, Kooijman 2010, Freitas et al. 2010). Energy intake estimates 136 were obtained using a conservative approach because we could hardly estimate the variance of the 137 ingestion rates, and the functional response type that needed to be selected is not precisely known 138 (i.e., it depends on multiple factors, see Valiela 1995). To do so, we assumed maximum intake that is 139 reached when prey abundance is very high and time lost for searching is zero. Note that in the 140 context of this study, a conservative approach means that an overestimation of the tuna ingestion 141 rate is preferred over an underestimation. The body mass distribution of ABFT was the most detailed 142 population information available (age or size structure data are lacking or more limited). Thus, we 143 focused on the relationship between ingestion rate (expressed in kJ per unit of time) and body mass.

144 Individual ingestion rate values were scaled up to the population level. To do this, ingestion rates $145\left(\mathrm{~kJ}^{*} \mathrm{day}^{-1}\right)$ were estimated from the DEB for the full body mass gamma distribution of sampled tuna. 146 Total annual ingestion rates for each body mass class $( \pm 1 \mathrm{~g})$ were then multiplied by their relative 147 frequency in the population (again based on the gamma distribution) and the annual tuna 148 abundance. The sum of those values was finally multiplied by the residence time of the population in 149 the Gulf of Lions.

\section{Tuna diet from stomach content analyses}

152 Stomach content analyses of tuna caught in the Gulf of Lions have been carried out annually from 1532011 to 2013. Tuna were captured between late-July and early-December of 2011 (n=42), 2012 $154(n=39)$ and $2013(n=37)$ by small-scale fisheries using longlines or handlines. Individuals were 155 measured $( \pm 1 \mathrm{~cm}$, fork length) and weighed $( \pm 0.1 \mathrm{~kg})$. Stomach contents were weighed and 
completely and partially intact prey identified to the lowest possible taxonomic level. Prey items were measured when possible (using total and/or standard length) and weighed to the nearest millimetre and gram. All otoliths (fish) and beaks (cephalopods) were collected to determine the total number of prey per species. For the three key prey species of this study (i.e. anchovy, sardine and sprat), otolith lengths were converted to prey item length, using linear relationships based on independent readings (see Supplementary files Table S1). Body mass of five key species was obtained by converting indirectly from size (sardine, anchovy and sprat) or directly (mackerel, squid) from otolith or beak length (using again independent readings, Supplementary files Table S1). Longline baits of undigested sardines of sizes $>17.5 \mathrm{~cm}$ were removed.

The importance of each prey species in the tuna diet was expressed as the percentage of prey composition by number $(\% \mathrm{~N})$, body mass $(\% \mathrm{M})$, and the frequency of occurrence of each item $(\% \mathrm{~F})$. For some rare species (referred to as "Other"), no body mass information was available so they were excluded when calculating \%M.

Feeding selectivity was calculated with the Chesson's index $\left(\alpha_{i}\right.$; Chesson 1978) for the 4 most abundant species:

$$
\alpha_{i}=\frac{\frac{r_{i}}{p_{i}}}{\sum_{j=1}^{k} \frac{r_{j}}{p_{j}}}
$$

where $r_{i}$ is the numerical proportion of prey species $i$ (among $k$ total prey species) and $p_{i}$ is the numerical proportion of this prey species in the environment. The index ranges between 0 and 1 (indicating complete avoidance and full selection, respectively), with $1 / k$ indicating neutral selection (here: 0.25).

Because our sampling size was limited ( 40 stomachs per year), interannual differences in diet might have been caused by small discrepancies in the annual sampling dates and tuna size. Therefore, we tested whether prey length (anchovy, sardine and sprat) could be related to sampling date or tuna 
178

179

180

181

182

183

184

185

186

187

188

189

190

191

192

193

194

195

196

197

198

199

200

size, using Spearman's rank correlation. We also tested whether the prey composition of the eight most frequently occurring species (expressed as $\% \mathrm{~N}$ ) could be related to the sampling date or tuna size, using a Mantel test to correlate the two dissimilarity matrices. The prey item matrix was created based on the Bray-Curtis method (as percentages are used, see Legendre and Legendre 1998) and Euclidean distances were used for the tuna size and sampling date matrix.

To estimate the energetic importance of sardine, anchovy and sprat in the diet of ABFT, it is necessary to also consider other relevant prey species (e.g., squid and mackerel). For example, a tuna whose stomach comprises $50 \%$ fat sardine and $50 \%$ small squid will acquire more energy from sardine than from squid. Thus, we must know the energetic density $(\mathrm{J} / \mathrm{g})$, body mass distribution and $\% \mathrm{M}$ of each major prey species consumed in order to estimate their energetic importance. Each body mass class $(0.5 \mathrm{~g})$ of a given prey species was multiplied by the energetic density of that species (see Appendix 1: Energetic density) and the relative frequency of that body mass class. These values were summed per species to obtain the energetic value $(\mathrm{J})$ of a standard individual, with which the number of individuals per species consumed by all tuna was found.

\section{Estimating prey abundance: small pelagic fish census}

Annual standardised acoustic and pelagic trawl surveys (PELagiques MEDiterranée, PELMED) have been carried out continuously since 1993 to estimate biomass and abundance of several small pelagic fish and to collect basic biological parameters. Sampling is performed in July along nine equidistant parallel transects perpendicular to the coastline, ranging between depths of $20 \mathrm{~m}$ and $200 \mathrm{~m}$. Here, we used resultant abundance estimates for sardine, anchovy, sprat and mackerel for 2011-2013 and biological data to calculate size distributions and morphometric relationships (e.g. a length-weight key to obtain prey item body mass) for these species (see Supplementary files Table S1, Fig. S4, Van Beveren et al. 2014, Saraux et al. 2014). 


\section{Predation pressure on small pelagic fish}

202 To obtain a percentage of "population consumption" (i.e. the percentage of each prey consumed by 203 ABFT at the population level), we divided the estimated total number of sardine, anchovy or sprat consumed by ABFT by their corresponding abundance in the NW Mediterranean. To reflect uncertainties in various estimates, all calculations were bootstrapped to estimate ABFT predation (10,000 iterations). To reflect various sources of uncertainty in the estimation of ABFT abundance in the Gulf of Lions (see Bauer et al. 2015), we used a uniform distribution spanning the $\pm 95 \%$ confidence intervals given by Bauer et al (2015). Because for 2013 no tuna abundance data was available, we took the interval between the lowest and highest interval limit established for 2011 and 2012 (i.e. the largest range between the interval limits of the previous years, Appendix 1). Additionally, a uniform distribution was also assigned to the prey energetic densities (between minimal and maximal values, Supplementary files Table S1), given that data were derived from literature that did not necessarily consider the same time and space domain. At last, other sources of uncertainty (e.g. such as associated with the DEB) were taken into account by taking a conservative attitude (see previously for the DEB).

ABFT selectivity for certain prey sizes was also investigated by comparing the size distributions of sardine, anchovy and sprat in ABFT stomachs with the size distributions of those obtained from the pelagic surveys. As the survey takes place in July and the tuna stomachs were collected from August to November, the theoretical sizes of anchovy and sardine ingested by tuna were back-calculated for comparative purposes, using age-length keys developed from PELMED otolith data (2008-2013, Supplementary files Fig. S4), and accounting for seasonal variability (Somers 1988, García-Berthou et al. 2012). This is important as small pelagic fish mainly grow in summer in this area. For sprat, an annual linear model was used as only data for two age classes were available, and the backcalculated difference in length was multiplied by 1.5 , a factor estimated from the anchovy data (Supplementary files Fig. S4). Also, ABFT consumed small-sized anchovy that could not be caught 
227 were smaller than $9 \mathrm{~cm}$ ). Therefore, when comparing the diet and population census size classes, 228 ingested individuals smaller than $9 \mathrm{~cm}$ were not considered. As data were unbalanced, non-normally 229 distributed and obtained from different sources, only the percentage of overlap of the two size 230 distributions was calculated, as well as the differences between the frequencies of each size 231 distributions (so positive values correspond to positive selection). 


\section{Results}

\section{Tuna diet and selectivity}

234 Length and mass of the tuna analysed for their stomach content ranged between $89 \mathrm{~cm}$ and $158 \mathrm{~cm}$ 235 and $12.5 \mathrm{~kg}$ and $51.2 \mathrm{~kg}$, respectively. Of the 118 stomachs examined, only one was found empty (in 236 2011). No significant relationships were found between prey composition and the sampling date or 237 tuna length ( $p>0.05$, Mantel test), nor between the prey length and the sampling date or tuna length 238 ( $>>0.05$, Spearman's correlation), so that year-to-year differences in prey length and composition could not be attributed to minor changes in these two factors.

In total, 5,099 prey items belonging to 29 prey species or families were identified, resulting in a mean prey abundance of 44 individuals per stomach. Anchovy and sardine were always the most important species in terms of abundance, body mass and frequency of occurrence, although these indices varied considerably between years (Fig. 2). Together they consistently accounted for more than $80 \%$ of ABFT diet (both in mass and number) in the area and each was present in at least $79 \%$ of the stomachs. In contrast, sprat was little present in 2011 and $2012(4 \% \mathrm{~N})$, but became relatively more important in $2013(14 \% \mathrm{~N})$. Cephalopods and mackerel only constituted between $1 \%$ and $3 \%$ of the

247 diet (for both mass and number).

According to the Chesson's index, ABFT generally selected anchovy and mackerel, rather than sardine and sprat (Fig. 2). Tuna always positively selected for anchovy, although this selection almost doubled between years (i.e., 2011 and 2013). Mackerel were both positively and negatively selected, depending on the year. Sardine and sprat were negatively selected (although sardine was preferred to sprat). During the three years, anchovy was the only prey species for which the proportion in the stomach fluctuated in parallel with its proportion in the ecosystem found by the pelagic survey. positive selectivity was also visible on small size classes in 2013, Fig. 3). No consistent or clear size 
256

257

258

259

260

261

262

263

264

265

266

267

268

269

270

271

272

273

274

275

276

277

278

279

selectivity was present for anchovy, as both size distributions found had a high level of overlap (6777\%). For sprat, there was a consistent difference between the two distributions over the three years, with a greater proportion of small individuals in the tuna diet. No clear size selectivity of ABFT (towards small or large preys) can thus be detected when considering the three dominant small pelagic fish species together.

\title{
Predation pressure on small pelagics
}

For ABFT between $4 \mathrm{~kg}$ and $86 \mathrm{~kg}$, the energetic requirement was ranging between $0.8 \% \mathrm{Mb}$ and 2.5 $\% \mathrm{Mb}$ (\% body mass*day-1), $758 \mathrm{Kj}^{*}$ day $^{-1}$ and $5870 \mathrm{Kj}^{*}$ day $^{-1}$ or $90 \mathrm{Kj}^{*} \mathrm{~kg}^{-1} * \mathrm{day}^{-1}$ and $190 \mathrm{Kj}^{*} \mathrm{~kg}^{-1} * \mathrm{day}^{-1}$. The body mass distribution of the part of the ABFT population under study (i.e., ABFT inhabiting the Gulf of Lions) had a median of $24.55 \mathrm{~kg}$ (Fig. 4a). At this median mass, individual tuna ingestion rates given by the DEB (Fig. 4b) were $2544 \mathrm{Kj}^{*}$ day $^{-1}, 103 \mathrm{Kj}^{*} \mathrm{~kg}^{-1} * \mathrm{day}^{-1}$ or dependent on the year (related to the prey composition and resulting average prey energetic density) $1.3-1.4 \% \mathrm{M}_{\mathrm{b}}$. Thus, given ABFT abundance and residence time in the study region, the total energetic requirement for ABFT was estimated at $6.78 \times 10^{6} \pm 1.47 \times 10^{6} \mathrm{MJ}$ on average over all three years.

Anchovy and sardine were the most important species in terms of caloric importance, given their relatively high caloric density (Supplementary files Table S1) and \%M (Fig. 2). The contribution of sprat, mackerel and especially cephalopods was secondary. Given the abundance of those species in the area (Table 1, based on pelagic survey data), the consumption by tuna represented a maximum of $1.93 \% \pm 0.55 \%$ of the anchovy, $0.61 \% \pm 0.23 \%$ of the sardine and $0.07 \% \pm 0.02 \%$ of the sprat populations (Table 1). Thus, the predation pressure of ABFT in the Gulf of Lions on their main prey species was low $(<2 \%$ of the prey populations).

\section{Discussion}

\author{
Effect on the abundance
}


Despite the fact that sardine and anchovy are the main prey of ABFT in the NW Mediterranean, the influence of predation pressure on the abundance of these species appears to be negligible $(<2 \%)$. Moreover, these predation pressure estimates are based on calculations performed for the three years (2011-2013) when tuna biomass was relatively high and sardine and anchovy biomass was already relatively low (Van Beveren et al. 2014, Bauer et al. 2015). Hence, in previous years (when ABFT abundance was smaller and the small pelagics ones often larger), tuna predation was likely to have been even smaller. In addition, we used a conservative approach that considered the high uncertainty around parameters, such as ABFT abundances (i.e., using a confidence interval of $\pm 95 \%$ ) and energetic densities (i.e., using the range between minimal and maximal values). Although no such uncertainty was included for the abundance of prey species in the area, values are thought to be underestimated rather than overestimated (e.g., due to undetected biomass in unsampled nearshore areas, Brehmer et al. 2006), thereby overestimating predation pressure. However, even if an additive underestimation of predation resulted from the errors that were not included (e.g., on the residence time), predation ratios would still remain too low to be considered as important. The natural top-down control of ABFT on its prey populations in the studied area is further much lower than this of the fisheries, even with sardine and anchovy not being overfished (GFCM 2011). Between 1995 and 2013 , on average, $13 \%$ of the anchovy and $9 \%$ of the sardine population abundance was fished annually, which is at least 6 to 10 times higher than the quantity consumed by ABFT. Thus, taking into account reasonable levels of uncertainty, our results excluded predation pressure by ABFT as the main cause for the recent changes in the sardine and anchovy populations of the Gulf of Lions.

\section{Effect on the size distribution}

If ABFT were to consume only the largest individuals, an effect on the size distribution of the prey species might have occurred. However, tuna appear to be opportunistic and have little prey size selectivity, as evidenced by a weak or inconsistent pattern of size selection between years and among species (a result in agreement with past studies on ABFT feeding in the Mediterranean Sea, see e.g. Karakulak et al. 2009). However, the size distributions of the small pelagic fish found in the 
stomach contents and those caught in the survey are not exactly comparable, possibly due to the

temporal mismatch between the small pelagic survey and the one on ABFT, as well as the lower size

limit on the small pelagic fishing gear (although both were corrected for). For example, anchovy

spawns between May and June (in contrast to winter spawning sardine and sprat) and these young-

of-the-year fish were by July (when the PELMED survey operates) still too small to be captured by the

size-restrictive mesh size. ABFT were generally captured later, when anchovy had already slightly

grown. Also, small discrepancies in the size distributions might result from spatial heterogeneity in size of the small pelagic fish populations and the tuna hunting area (e.g., tuna might hunt in a zone were small pelagic fish are not averaged sized). Thus, we can conclude that observed differences consumption of certain size classes by tuna and that the size distributions of the small pelagic fish are not likely to have been affected by tuna predation.

\section{Tuna energy requirement}

Assessing predation pressure is particularly challenging for pelagic fish, as their abundance and the daily energy requirement of their predator are not easily estimated. Here, predation estimates were possible due to the availability of a calibrated model and a large amount of diverse multi-annual data sources, including stomach content samples of $A B F T$, size distribution data of both preys and predator and abundance estimates from extensive acoustic and aerial surveys.

The DEB model provided us with energy intake estimates by weight of Mediterranean bluefin tuna, which were unavailable so far. For tuna, information on energetics lags far behind on other smaller species because of its size and difficulty of handling. Several of the studies estimating tuna energy requirement (see next paragraph) used caging experiments. Obviously, such analyses are expensive, time consuming and impossible on many locations. Only Essington et al. (2002) did not use caging experiments, but a bio-energetic model to Yellowfin tuna (Thunnys albacares). Although the 
331 they still used a heavy dataset and relied on several previously published values and equations.

332 Additionally, other methods exist to estimate energy intake that have not yet been applied to tuna, 333 including stomach content analysis (e.g. Elliott \& Persson 1978), contaminant mass balance analyses 334 (e.g. Trudel et al. 2011), regression models (e.g. Palomares \& Pauly 1998) or a combination of 335 different approaches (Ferriss \& Essington 2014). Each of these methods has its proper limitations. In 336 our case, the DEB model was the preferred approach, given that a lot of extra data collection or 337 caging experiments would have been needed elsewise, that it is more general than the previously 338 used bio-energetic models (e.g. Essington 2002) and that results so far have been shown to be 339 promising.

We found that ABFT between $4 \mathrm{~kg}$ and $86 \mathrm{~kg}$ (i.e. between 1.5 and 9.2 years) consume about $0.8 \% \mathrm{M}_{\mathrm{b}}$ to $2.5 \% \mathrm{M}_{\mathrm{b}}$, i.e. about $181 \mathrm{kcal}$ to $1403 \mathrm{kcal}$ (or $758 \mathrm{~kJ}$ to $5870 \mathrm{~kJ}$ ) daily. The estimates of \% $\mathrm{M}_{\mathrm{b}}$ are in the lower range of results from previous studies on other tuna species (Glencross et al. 2002, Essington et al. 2002, Wexler et al. 2003, Takii et al. 2005, Fitzgibbon et al. 2007). For example, Essington et al. (2002) reported daily consumption rates of $3.5-6 \% \mathrm{M}_{\mathrm{b}}$ for $0.5-6$ year old yellowfin tuna, while Wexler et al. (2003) described rates of $1-10 \% \mathrm{M}_{\mathrm{b}}$ for yellowfin of $1-6 \mathrm{~kg}$. For a more closely related species, the southern bluefin tuna (Thunnus maccoyii), Fitzgibbon et al. (2007) estimated a daily consumption of $2-9 \% \mathrm{M}_{\mathrm{b}}$ for fish of around $10 \mathrm{~kg}$. ABFT individuals in this study were generally larger (about $26 \mathrm{~kg}$ on average) and were exposed to different ambient temperatures, two factors that greatly alter the energetic requirements of tuna. Smaller fish consume fewer calories but have a higher energetic need relative to their mass and the endothermic system of tuna includes a specific relationship between ambient temperature and metabolic rate (Blank et al. 2007). Additionally, $\% \mathrm{M}_{\mathrm{b}}$ depends on the energetic density of the food ingested and captive individuals might have an increased metabolic rate because of stress. But even considering the maximum reported ingestion rate found in literature $\left(0.43 \mathrm{MJ}^{*} \mathrm{~kg}^{-1} * \mathrm{day}^{-1}\right.$, Wexler et al. 2003), reported for small yellowfin and thus theoretically overestimating ingestion values for larger ABFT, the estimated predation pressure of ABFT on small pelagic fish would still be relatively low $(<10 \%)$. 


\section{Atlantic bluefin tuna diet}

358

359

360

361

362

363

364

365

366

367

368

369

370

371

372

373

374

375

376

377

378

379

380

381

382

In contrast to studies on tuna energy requirements, studies on the diet composition of ABFT are ample (e.g., Karakulak et al. 2009, Varela et al. 2013). As the diet of tuna varies significantly between years, seasons, regions and life stages, our results deviated from other studies. For example, other studies from the Mediterranean found more empty stomachs (Varela et al. 2013) supporting the hypothesis that the Gulf of Lions act as an important feeding area for juvenile tuna (Druon et al. 2011, Fromentin and Lopuszanski 2014). Our results are consistent with other studies that found that ABFT prey composition is diverse but dominated by few species, that differ among ABFT feeding grounds (Fromentin and Powers 2005). However, we found a predominance of sardine and anchovy in the diet (e.g., up to $76 \% \mathrm{~N}$ of anchovy), as opposed to more elevated feeding on cephalopods and/or crustaceans highlighted in other Mediterranean areas (Sinopoli et al. 2004, Sarà and Sarà 2007, Goñi et al. 2011, de la Serna et al. 2012). Cephalopods were of limited importance $(<4 \% \mathrm{~N})$ and crustaceans were rarely encountered $(<1 \% \mathrm{~N})$. This may be partly because tuna sampling for stomach analyses of this study was limited to the shelf of the Gulf of Lions and could thus not fully reflect the prey composition of ABFT in the NW Mediterranean. Note, however, that our results are in agreement with past studies, which also found a dominance of anchovy in ABFT stomachs from the Gulf of Lions and other nursery areas, such as the Bay of Biscay (Fromentin and Powers 2005).

Although tuna are generally considered to be opportunistic predators (Crane 1936), the individuals in this study appeared to negatively select sardine and sprat and positively select anchovy (a similar finding was suggested for albacore, Thunnus alalunga, in the bay of Biscay; Goñi et al. 2011). This is surprising as sprat has a higher fat content than anchovy (Brosset et al. 2014). Therefore, this apparent selection may actually be due to a difference in the geographic distribution and/or behaviour of the prey species, or an error in the relative abundance estimates of the prey in the environment (see before) or the stomachs. For example, sardine and sprat in the Gulf of Lions are more coastal than anchovy and depths of $150 \mathrm{~m}$ to $200 \mathrm{~m}$ are unfavourable to them (Saraux et al. 2014). Furthermore, sardine and anchovy might be different in terms of behaviour and movement, 
so that anchovy are when hunted more easily caught. For instance, diurnal differences in densities of both populations have been previously reported (Barange and Hampton 1997, Saraux et al. 2014), possibly resulting in a dissimilar predation risk. Additionally, a larger tuna stomach sampling effort would have better covered variables such as time and space. Although our sampling size is fully comparable (and sometimes higher) to those of previous studies on tuna stomach analyses, more samples would have resulted in less uncertainty., We also found that when the relative proportion of sardine in the ecosystem increases this does not relate to a concurrent increase in their relative consumption by tuna. This might be because sardine are coastal and when their relative proportion in the ecosystem is higher, they may increase school densities rather than expand their spatial distribution to areas where tuna hunts more intensely (Saraux et al. 2014).

In conclusion, we provided an integrative framework based on previously developed techniques for conducting predator-prey analyses. Such a state-of-the-art framework has not yet been used to estimate predation pressure in the marine environment, and could further be applied to other preypredator studies, with some input estimates perhaps being obtained through an equivalent approach (e.g. to estimate prey or predator abundance, or by the use of a simpler less data-consuming energetic model such as empirical regression models). In this case, the effect of tuna predation on the small pelagic fish populations was found to be extremely small, so this specific ecosystem considerations would not affect the fishery management.

\section{Acknowledgements}

We thank the captain and the crew of the RV "L'Europe" as well as all the scientists on board for their assistance during the PELMED surveys. PELMED surveys are cofinanced by Europe through the Data Collection Framework. The aerial surveys were funded by the convention Ifremer - Direction des Pêches Maritimes et de l'Aquaculture (French administration) from 2009 onwards. We are grateful as well for the funding of the MERMEX project and France Filière Pêche (FFP) for the stomach analyses. Also, we thank the two anonymous reviewers for their careful review of the manuscript and their 
408 excellent suggestions. This work is a part of the program Study of the Pelagic ecosystem in the Gulf of 409 Lions (EcoPelGol), financed by France Filière Pêche. M.J. acknowledges support from Japan Society 410 for the Promotion of Science (JSPS) Postdoctoral Fellowship Program for Foreign Researchers no. 411 P13380 and an accompanying Grant-in-Aid for Scientific Research. 
412

413

414

415

416

417

418

419

420

421

422

423

424

425

426

427

428

429

430

431

432

433

434

435

436

437

438

439

440

441

442

443

444

445

446

447

448

449

450

451

452

453

454

455

456

457

458

459

460

461

\section{References}

Bailey, K.M., Ciannelli, L., Hunsicker, M., Rindorf, A., Neuenfeldt, S., Möllmann, C., Guichard, F., and Huse, G. 2010. Comparative analysis of marine ecosystems: workshop on predator-prey interactions. Biol. Lett. 6(5): 579-581. doi:10.1098/rsbl.2010.0326.

Bănaru, D., Mellon-Duval, C., Roos, D., Bigot, J.-L., Souplet, A., Jadaud, A., Beaubrun, P., and Fromentin, J.-M. 2013. Trophic structure in the Gulf of Lions marine ecosystem (northwestern Mediterranean Sea) and fishing impacts. J. Mar. Syst. 111-112: 45-68. doi:10.1016/j.jmarsys.2012.09.010.

Barange, M., and Hampton, I. 1997. Spatial structure of co-occurring anchovy and sardine populations from acoustic data: implications for survey design. Fish. Oceanogr. 6(2): 94-108. doi:10.1046/j.1365-2419.1997.00032.x.

Bauer, R.K., Bonhommeau, S., Brisset, B., and Fromentin, J.-M. 2015. Aerial surveys to monitor bluefin tuna abundance and track efficiency of management measures. Mar. Ecol. Prog. Ser. doi:10.3354/meps11392.

Blank, J.M., Farwell, C.J., Morrissette, J.M., Schallert, R.J., and Block, B.A. 2007. Influence of swimming speed on metabolic rates of juvenile Pacific bluefin tuna and yellowfin tuna. Physiol. Biochem. Zool. 80(2): 167-177. doi:10.1086/510637.

Brehmer, P., Guillard, J., Guennegan, Y., Bigot, J.L., and Liorzou, B. 2006. Evidence of a variable "unsampled" pelagic fish biomass in shallow water $(<20 \mathrm{~m})$ : the case of the Gulf of Lion. ICES J. Mar. Sci. 63(3): 444-451. doi:10.1016/j.icesjms.2005.10.016.

Brosset, P., Fromentin, J.-M., Ménard, F., Pernet, F., Bourdeix, J.-H., Bigot, J.-L., Van Beveren, E., Pérez Roda, M.A., Choy, S., and Saraux, C. 2014. Measurement and analysis of small pelagic fish condition: A suitable method for rapid evaluation in the field. J. Exp. Mar. Biol. Ecol. 462: 90-97. doi:10.1016/j.jembe.2014.10.016.

Brosset, P., Le Bourg, B., Costalago, D., Bănaru, D., Van Beveren, E., Bourdeix, J.-H., Fromentin, J.-M., Ménard, F., and Saraux, C. 2016. Linking small pelagic dietary shifts with ecosystem changes in the Gulf of Lions. Mar. Ecol. Prog. Ser. 554: 157-171. doi:10.3354/meps11796.

Brosset, P., Ménard, F., Fromentin, J.-M., Bonhommeau, S., Ulses, C., Bourdeix, J.-H., Bigot, J.-L., Van Beveren, E., Roos, D., and Saraux, C. 2015. Influence of environmental variability and age on the body condition of small pelagic fish in the Gulf of Lions. Mar. Ecol. Prog. Ser. 529: 219231. doi:10.3354/meps11275.

Chesson, J. 1978. Measuring Preference in Selective Predation. Ecology 59(2): 211-215. doi:10.2307/1936364.

Crane, J. 1936. Notes on the biology and ecology of giant tuna Thunnus thynnus L., observed at Portland, Maine. Zoologica 212: 207-212.

Cury, P.M., Shin, Y.-J., Planque, B., Durant, J.M., Fromentin, J.-M., Kramer-Schadt, S., Stenseth, N.C., Travers, M., and Grimm, V. 2008. Ecosystem oceanography for global change in fisheries. Trends Ecol. Evol. 23(6): 338-346. doi:10.1016/j.tree.2008.02.005.

David, L., and Di-Méglio, N. 2013. Important areas for the conservation of cetaceans in the Gulf of Lions shelf and slope area: synthesis of existing data on cetaceans and threats. UNEP-MAPRAC/SPA, Tunis.

Druon, J.-N., Fromentin, J.-M., Aulanier, F., and Heikkonen, J. 2011. Potential feeding and spawning habitats of Atlantic bluefin tuna in the Mediterranean Sea. Mar. Ecol. Prog. Ser. 439: 223240. doi:10.3354/meps09321.

Essington, T.E., Kitchell, J.F., and Walters, C.J. 2001. The von Bertalanffy growth function, bioenergetics, and the consumption rates of fish. Can. J. Fish. Aquat. Sci. 58(11): 2129-2138. doi:10.1139/f01-151.

Essington, T.E., Schindler, D.E., Olson, R.J., Kitchell, J.F., Boggs, C., and Hilborn, R. 2002. Alternative fisheries and the predation rate of yellowfin tuna in the eastern Pacific ocean. Ecol. Appl. 12(3): 724-734. doi:10.1890/1051-0761(2002)012[0724:AFATPR]2.0.CO;2. 
462

463

464

465

466

467

468

469

470

471

472

473

474

475

476

477

478

479

480

481

482

483

484

485

486

487

488

489

490

491

492

493

494

495

496

497

498

499

500

501

502

503

504

505

506

507

508

509

510

511

Fitzgibbon, Q.P., Seymour, R.S., Ellis, D., and Buchanan, J. 2007. The energetic consequence of specific dynamic action in southern bluefin tuna Thunnus maccoyii. J. Exp. Biol. 210(2): 290298. doi:10.1242/jeb.02641.

Fromentin, J.-M. 2003. Why uncertainty in the management of the East Atlantic Bluefin tuna has constantly increased in the past few years. Sci. Mar. 67: 51-62.

Fromentin, J.-M., Bonhommeau, S., Arrizabalaga, H., and Kell, L.T. 2014. The spectre of uncertainty in management of exploited fish stocks: The illustrative case of Atlantic bluefin tuna. Mar. Policy 47: 8-14. doi:10.1016/j.marpol.2014.01.018.

Fromentin, J.-M., and Lopuszanski, D. 2014. Migration, residency, and homing of bluefin tuna in the western Mediterranean Sea. ICES J. Mar. Sci. doi:10.1093/icesjms/fst157.

Fromentin, J.-M., and Powers, J.E. 2005. Atlantic bluefin tuna: population dynamics, ecology, fisheries and management. Fish Fish. 6(4): 281-306. doi:10.1111/j.1467-2979.2005.00197.x.

García-Berthou, E., Carmona-Catot, G., Merciai, R., and Ogle, D.H. 2012. A technical note on seasonal growth models. Rev. Fish Biol. Fish. 22(3): 635-640. doi:10.1007/s11160-012-9262-x.

GFCM. 2011. Report of the working group on stock assessment of small pelagic species. Chania, Crete (Greece).

Glencross, B.D., Carter, C.G., Gunn, J., van Barneveld, R.J., Rough, K., and Clarke, S.M. 2002. Southern bluefin tuna, Thunnus maccoyii. In Nutrient Requirements and Feeding of Finfish for Aquaculture. CABI publishing, New York, US. pp. 159-171.

Goñi, N., Logan, J., Arrizabalaga, H., Jarry, M., and Lutcavage, M. 2011. Variability of albacore (Thunnus alalunga) diet in the Northeast Atlantic and Mediterranean Sea. Mar. Biol. 158(5): 1057-1073. doi:10.1007/s00227-011-1630-x.

Jusup, M., Klanjšček, T., and Matsuda, H. 2014. Simple measurements reveal the feeding history, the onset of reproduction, and energy conversion efficiencies in captive bluefin tuna. J. Sea Res. 94: 144-155. doi:10.1016/j.seares.2014.09.002.

Jusup, M., Klanjscek, T., Matsuda, H., and Kooijman, S.A.L.M. 2011. A Full Lifecycle Bioenergetic Model for Bluefin Tuna. PLoS ONE 6(7): e21903. doi:10.1371/journal.pone.0021903.

Karakulak, F.S., Salman, A., and Oray, I.K. 2009. Diet composition of bluefin tuna (Thunnus thynnus L. 1758) in the Eastern Mediterranean Sea, Turkey. J. Appl. Ichthyol. 25: 757-761.

Kooijman, S.A.L.M. 2010. Dynamic energy budget theory for metabolic organisation. Cambridge University Press.

Legendre, P., and Legendre, L.F.J. 1998. Numerical Ecology. In 2nd edition. Elsevier Science.

Mann, K.H., and Lazier, J.R.N. 2005. Dynamics of Marine Ecosystems: Biological-Physical Interactions in the Oceans. In 3 edition. Wiley-Blackwell, Malden, MA.

Nisbet, R.M., Muller, E.B., Lika, K., and Kooijman, S. a. L.M. 2000. From molecules to ecosystems through dynamic energy budget models. J. Anim. Ecol. 69(6): 913-926. doi:10.1111/j.13652656.2000.00448.x.

Pinkas, L., Oliphant, M.S., and Iverson, I.L.K. 1970. Food Habits of Albacore, Bluefin Tuna, and Bonito In California Waters. Fish Bull. 152: 1-105.

Planque, B., Fromentin, J.-M., Cury, P., Drinkwater, K.F., Jennings, S., Perry, R.I., and Kifani, S. 2010. How does fishing alter marine populations and ecosystems sensitivity to climate? J. Mar. Syst. 79(3-4): 403-417. doi:10.1016/j.jmarsys.2008.12.018.

Praca, E., and Gannier, A. 2008. Ecological niches of three teuthophageous odontocetes in the northwestern Mediterranean Sea. Ocean Sci. 4(1): 49-59. doi:10.5194/os-4-49-2008.

Sarà, G., and Sarà, R. 2007. Feeding habits and trophic levels of bluefin tuna Thunnus thynnus of different size classes in the Mediterranean Sea. J. Appl. Ichthyol. 23(2): 122-127. doi:10.1111/j.1439-0426.2006.00829.x.

Saraux, C., Fromentin, J.-M., Bigot, J.-L., Bourdeix, J.-H., Morfin, M., Roos, D., Van Beveren, E., and Bez, N. 2014. Spatial Structure and Distribution of Small Pelagic Fish in the Northwestern Mediterranean Sea. PLoS ONE 9(11): e111211. doi:10.1371/journal.pone.0111211. 
de la Serna, J.M., Godoy, M.D., Olaso, I., Zabala, J., Majuelos, E., and Báez, J.C. 2012. PRELIMINARY STUDY ON THE FEEDING OF BLUEFIN TUNA (THUNNUS THYNNUS) IN THE MEDITERRANEAN AND THE STRAIT OF GIBRALTAR AREA. Collect Vol Sci Pap ICCAT 68(1): 115-132.

Sinopoli, M., Pipitone, C., Campagnuolo, S., Campo, D., Castriota, L., Mostarda, E., and Andaloro, F. 2004. Diet of young-of-the-year bluefin tuna, Thunnus thynnus (Linnaeus, 1758), in the southern Tyrrhenian (Mediterranean) Sea. J. Appl. Ichthyol. 20(4): 310-313. doi:10.1111/j.1439-0426.2004.00554.x.

Somers, I.F. 1988. On a seasonally oscillating growth function. Fishbyte 6: 8-11.

Sousa, T., Domingos, T., and Kooijman, S. a. L.M. 2008. From empirical patterns to theory: a formal metabolic theory of life. Philos. Trans. R. Soc. Lond. B Biol. Sci. 363(1502): 2453-2464. doi:10.1098/rstb.2007.2230.

Sousa, T., Domingos, T., Poggiale, J.-C., and Kooijman, S. a. L.M. 2010. Dynamic energy budget theory restores coherence in biology. Philos. Trans. R. Soc. Lond. B Biol. Sci. 365(1557): 3413-3428. doi:10.1098/rstb.2010.0166.

Takii, K., Hosokawa, H., Shimeno, S., Ukawa, M., Kotani, A., and Yamada, Y. 2005. Anesthesia, fasting tolerance, and nutrient requirement of juvenile northern bluefin tuna. Fish. Sci. 71(3): 499503. doi:10.1111/j.1444-2906.2005.00993.x.

Thomas, L., Buckland, S.T., Burnham, K.P., Anderson, D.R., Laake, J.L., Borchers, D.L., and Strindberg, S. 2012. Distance sampling. In Encyclopedia of environmetrics, 2nd edition. Edited by A.H. ElShaarawi and W. Piegorsch. John Wiley \& Sons, Chichester. pp. 687-697.

Valiela, I. 1995. Feeding and Responses to Food Abundance. In Marine Ecological Processes. Springer New York. pp. 133-163. Available from http://link.springer.com/chapter/10.1007/978-14757-4125-4_5 [accessed 6 January 2016].

Van Beveren, E., Bonhommeau, S., Fromentin, J.-M., Bigot, J.-L., Bourdeix, J.-H., Brosset, P., Roos, D., and Saraux, C. 2014. Rapid changes in growth, condition, size and age of small pelagic fish in the Mediterranean. Mar. Biol. 161(8): 1809-1822. doi:10.1007/s00227-014-2463-1.

Van Beveren, E., Fromentin, J.-M., Bonhommeau, S., Rouyer, T., Brosset, P., and Saraux, C. 2016a. The fisheries history of small pelagics in the Northern Mediterranean. ICES J. Mar. Sci. doi:10.1093/icesjms/fsw023.

Van Beveren, E., Keck, N., Fromentin, J.-M., Laurence, S., Boulet, H., Labrut, S., Baud, M., Bigarré, L., Brosset, P., and Saraux, C. 2016b. Can pathogens alter the population dynamics of sardine in the NW Mediterranean? Mar. Biol. doi:10.1007/s00227-016-3015-7.

Varela, J.L., Rodríguez-Marín, E., and Medina, A. 2013. Estimating diets of pre-spawning Atlantic bluefin tuna from stomach content and stable isotope analyses. J. Sea Res. 76: 187-192. doi:10.1016/j.seares.2012.09.002.

Wexler, J.B., Scholey, V.P., Olson, R.J., Margulies, D., Nakazawa, A., and Suter, J.M. 2003. Tank culture of yellowfin tuna, Thunnus albacares: developing a spawning population for research purposes. Aquaculture 220(1-4): 327-353. doi:10.1016/S0044-8486(02)00429-5.

White, J.W. 2007. Spatially correlated recruitment of a marine predator and its prey shapes the largescale pattern of density-dependent prey mortality. Ecol. Lett. 10(11): 1054-1065. doi:10.1111/j.1461-0248.2007.01098.x. 


\section{Tables}

556 Table 1. The annual percentage of population consumption, ecosystem abundance and total number

557 consumed by tuna (Thunnus thynnus) of anchovy (Engraulis encrasicolus), sardine (Sardina 558 pilchardus) and sprat (Sprattus sprattus).

\begin{tabular}{|c|c|c|c|}
\hline \multicolumn{4}{|c|}{ Total abundance consumed by tuna (millions) } \\
\hline & $\underline{2011}$ & $\underline{2012}$ & $\underline{2013}$ \\
\hline Anchovy & $69.6 \pm 19.8$ & $27.1 \pm 9.6$ & $25.0 \pm 9.4$ \\
\hline Sardine & $33.7 \pm 9.6$ & $39.8 \pm 14.1$ & $48.6 \pm 18.3$ \\
\hline Sprat & $4.0 \pm 1.2$ & $1.6 \pm 0.6$ & $6.1 \pm 2.3$ \\
\hline \multicolumn{4}{|c|}{ Ecosystem abundance (millions) } \\
\hline & $\underline{2011}$ & $\underline{2012}$ & $\underline{2013}$ \\
\hline Anchovy & 3601 & 5142 & 2685 \\
\hline Sardine & 5655 & 9370 & 7927 \\
\hline Sprat & 5577 & 4649 & 9969 \\
\hline \multicolumn{4}{|c|}{ Population consumption } \\
\hline & $\underline{2011}$ & $\underline{2012}$ & $\underline{2013}$ \\
\hline Anchovy & $1.93 \pm 0.55 \%$ & $0.53 \pm 0.19 \%$ & $0.93 \pm 0.35 \%$ \\
\hline Sardine & $0.60 \pm 0.17 \%$ & $0.42 \pm 0.15 \%$ & $0.61 \pm 0.23 \%$ \\
\hline Sprat & $0.07 \pm 0.02 \%$ & $0.01 \pm 0.00 \%$ & $0.06 \pm 0.02 \%$ \\
\hline
\end{tabular}

559

560 


\section{$561 \quad$ Figures}
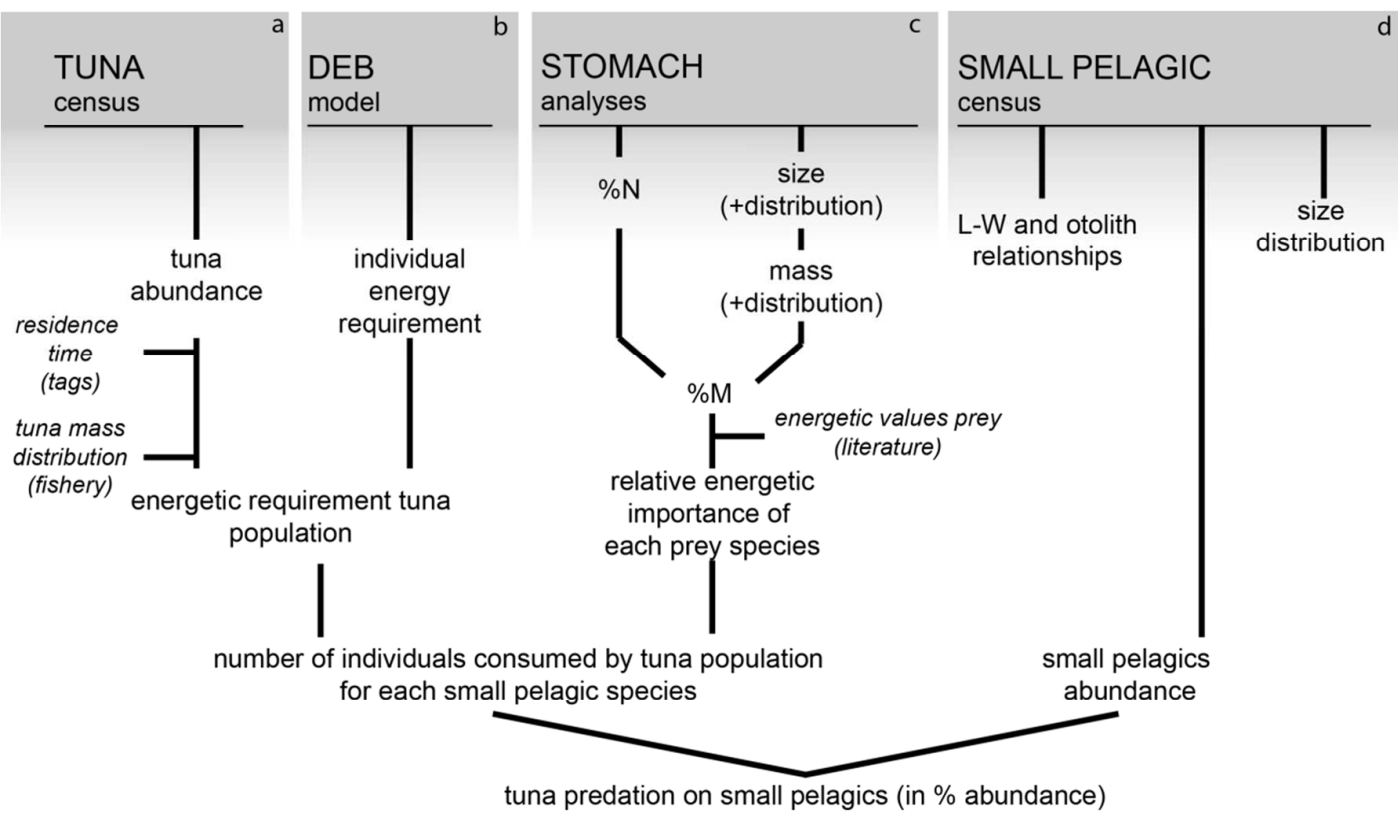

562 tuna predation on small pelagics (in \% abundance)

563 Fig 1. Schematic representation of the data/estimates and the analyses to calculate the percentage

564 of abundance of each small pelagic population consumed by tuna (Thunnus thynnus). Each of the

565 four blocks ( $a, b, c$ and d) represents a major data source, from which the ensuing information

$566 \quad$ was obtained. Smaller data sources are indicated in italics. 

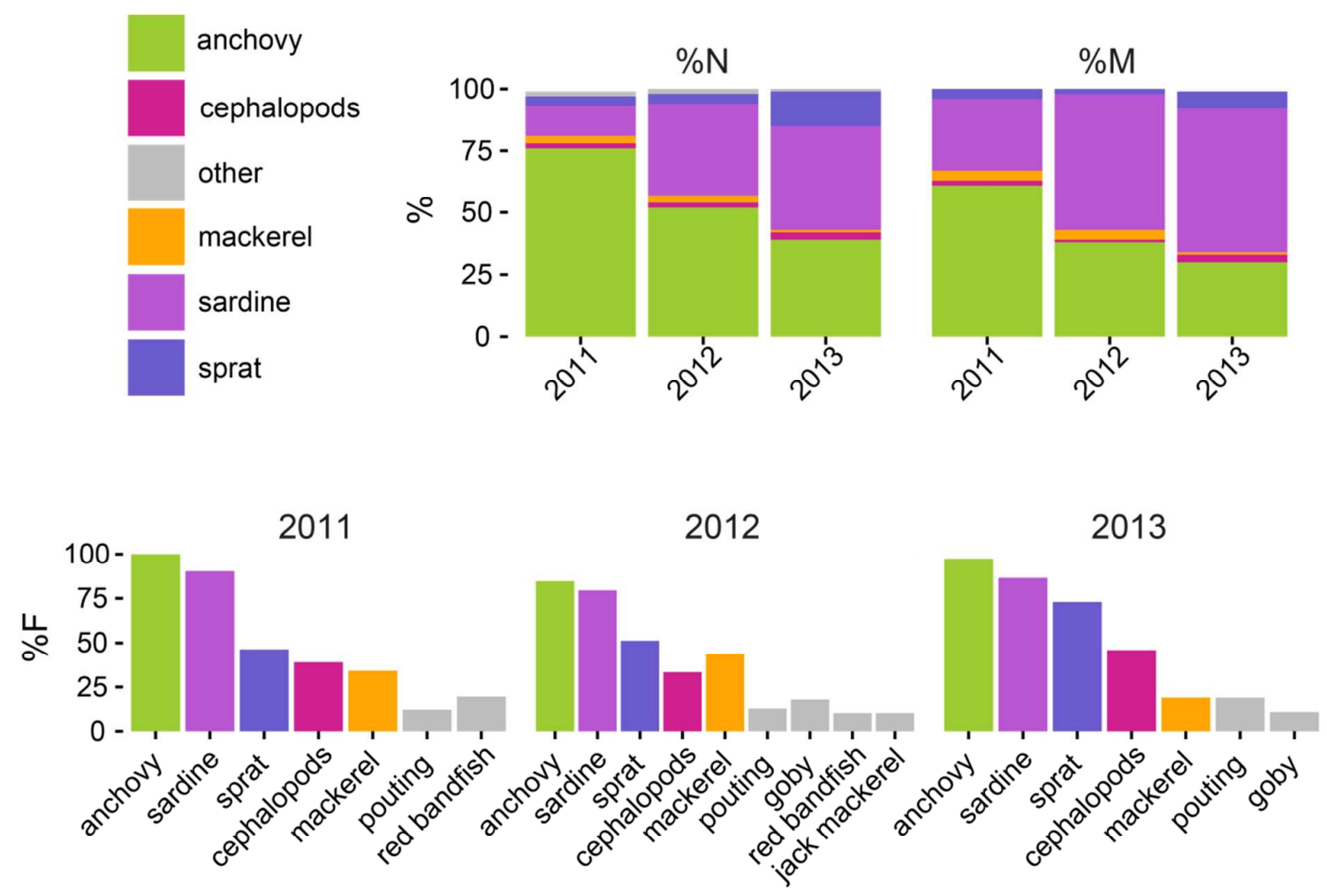

568

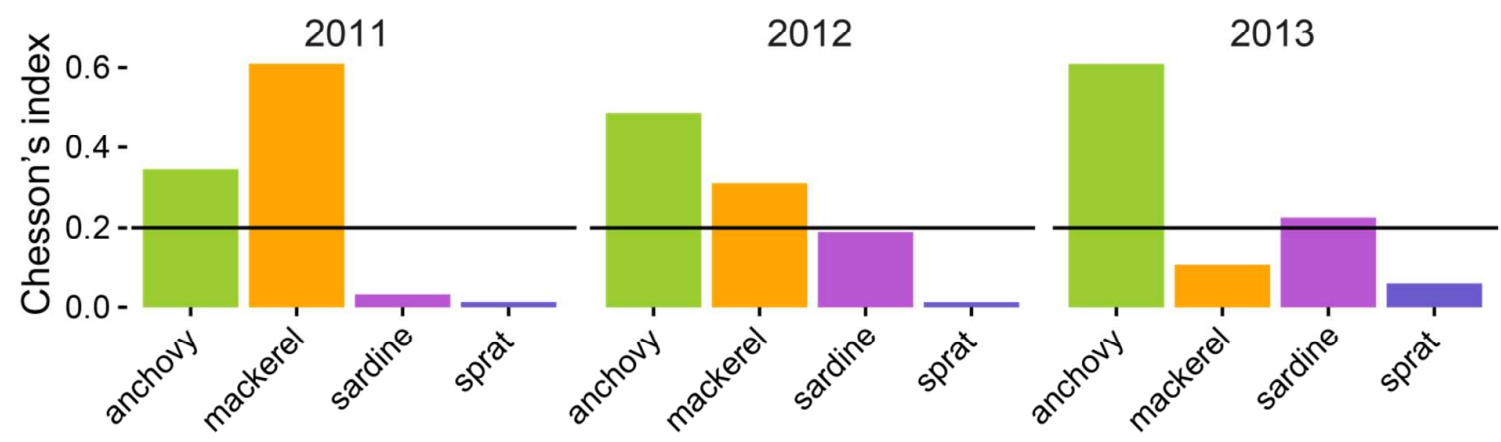

Fig 2. Annual results of the stomach analyses (2011-2013): the prey's relative abundance (\%N), mass (\%M), occurrence (\%F) and Chesson's selectivity index, with the horizontal line indicating neutral selectivity $\left(\alpha_{i}=0.25\right)$. The "other" class groups all species less abundant than $1 \% \mathrm{~N}$. The relative mass of this group is unknown and thus not included when calculating \%M. Chesson's index is given only for species whose proportion in the ecosystem is known (based on the prey population census) and the percentage of occurrence is given only for the most prevalent species $(\% \mathrm{~F}>10)$, i.e. sardine (Sardina pilchardus), anchovy (Engraulis encrasicolus), sprat (Sprattus sprattus), pouting (Trisopterus luscus), goby (Family Gobiidae), hake (Merluccius merluccius), jack 
577 mackerel (Trachurus spp.), red bandfish (Cepola macrophthalma), mackerel (Scomber colias and $578 \quad$ S. scombrus) and cephalopods (mostly Illex spp.).

579 


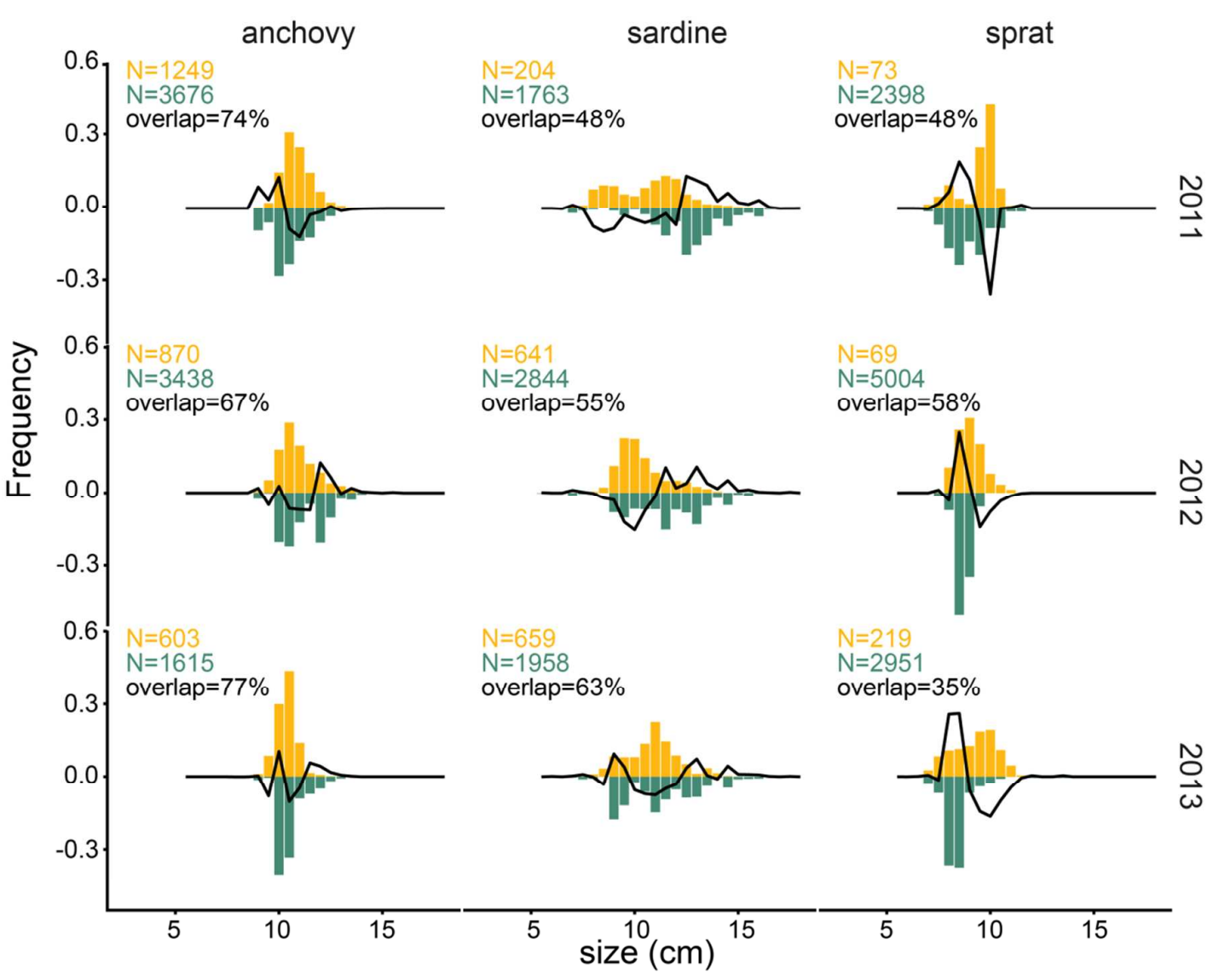

581 Fig 3. Size distributions per year and per species, i.e. sardine (Sardina pilchardus), anchovy

(Engraulis encrasicolus) and sprat (Sprattus sprattus), found in the stomachs of Atlantic bluefin tuna (Thunnus thynnus) (green and made negative) and by the small pelagic survey (orange). Small anchovy $(<9 \mathrm{~cm})$ were removed (see material and methods). The black line is the difference between the frequencies of each size class (positive values correspond to positive size selectivity by tuna). The numbers of individuals sampled is indicated $(\mathrm{N})$, as well as the percentage of overlap of the two distributions. 

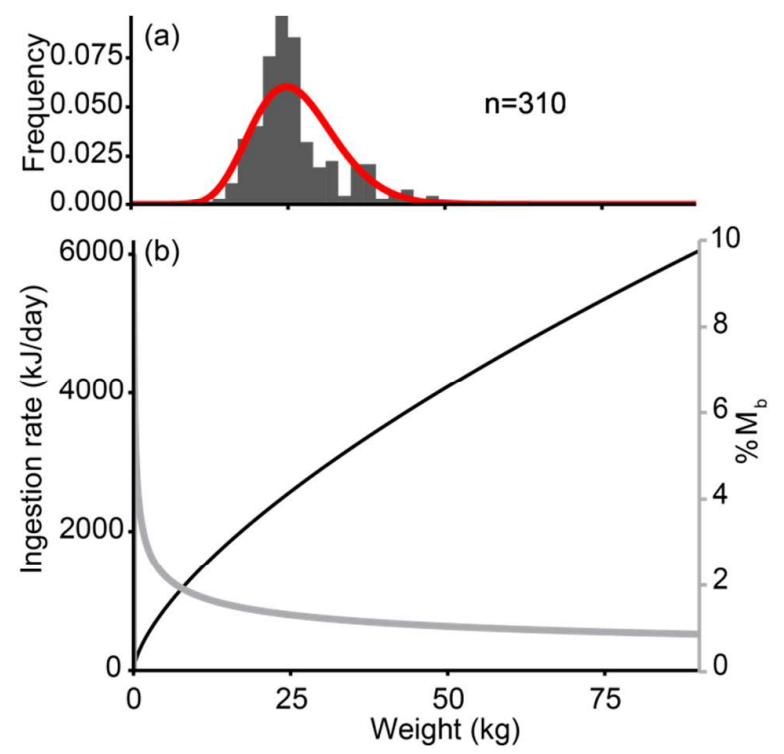

589 Fig 4. (a) The mass distribution of Atlantic bluefin tuna (Thunnus thynnus) juveniles and (b) tuna mass as a function of their ingestion rate (black line) and percentage of body mass consumed

591 $\left(\% \mathrm{M}_{b}\right.$, grey line). The bottom figure is the final output of the Dynamic Energy Budget model, for the range of tuna mass observed in the Gulf of Lions.

593 


\section{Canadian Journal of Fisheries and Aquatic Sciences}

Appendices

\section{Prey predator interactions in the face of management regulations: changes in Mediterranean small pelagics are not due to increased tuna predation}

Elisabeth Van Beveren, Jean-Marc Fromentin, Sylvain Bonhommeau, Anne-Elise Nieblas, Luisa Metral, Blandine Brisset, Marko Jusup, Robert Klaus Bauer, Pablo Brosset, Claire Saraux 


\section{Appendix 1}

\section{Material and methods}

Tuna abundance

Annual aerial surveys have been performed between June and October from 2000 to 2003 and from 2009 until present in the Gulf of Lions to construct a unique fishery-independent index of tuna density (Fromentin et al. 2003; Bonhommeau et al. 2010; Fromentin, Bonhommeau \& Brisset 2013; Bauer et al. 2015). Using the annual estimates of bluefin tuna densities given by Bauer et al. (2015), we calculated the abundance of tuna in the studied area by simply multiplying those annual densities with the surface area of the aerial survey transects. We did not account for the differences in spatial coverage of the small pelagic fish surveys $(<200 \mathrm{~m}$ ) and the tuna surveys (including waters $>200 \mathrm{~m}$ ) as small pelagic fish are primarily concentrated over the continental shelf (Saraux et al. 2014), and an increased survey area would not significantly affect the estimates of abundance or biomass of these species.

\section{Energetic density}

To consider the energetic importance of the prey species of interest in the tuna diet, information on the energetic density and body mass distribution of the other main prey species needs to be known as well. Therefore, all prey species that constituted more than $1 \% \mathrm{~N}$ of the tuna diet over a three year period were also examined, accounting for $98.3 \% \mathrm{~N}$ of the prey consumption. Multiple species of mackerel $(97.5 \% \mathrm{~N}$ Scomber japonicus and 2.5\%N S. scombrus) and cephalopods (mostly Illex coindetii and some other Illex spp., as well as some Todaropsis eblanae) were grouped because individuals were not often identified to the species level and species-specific otolith length versus body length relationships and energetic densities were not available.

Energetic densities (kJ/g of wet weight) were obtained from the literature for sardine (Rosa et al. 2010; Harmelin et al. 2012; Spitz \& Jouma'a 2013), anchovy (Tirelli et al. 2006; Dubreuil \& Petitgas 2009; Harmelin et al. 2012; Spitz \& Jouma'a 2013), sprat (Hislop, Harris \& Smith 1991; Arrhenius 1998; Spitz \& Jouma'a 2013), mackerel (Montevecchi et al. 1984; Spitz \& Jouma'a 2013) and cephalopods (Lawson, Magalhes \& Miller 1998; Eder \& Lewis 2005; Ciancio, Pascual \& Beauchamp 2007). As energetic densities may change considerably between seasons, places and individuals (e.g., because of differences in length or condition), maximal and minimal values were noted (Table S1) and a uniform distribution between these two values was used, rather than the average, to represent the energetic values of the prey species, thereby accounting for some uncertainty. 


\section{References}

Arrhenius, F. (1998) Food intake and seasonal changes in energy content of young Baltic Sea sprat (Sprattus sprattus L.). ICES Journal of Marine Science, 55, 319-324.

Bauer, R.K., Bonhommeau, S., Brisset, B. \& Fromentin, J.-M. (2015) Aerial surveys to monitor bluefin tuna abundance and track efficiency of management measures. Marine Ecology Progress Series.

Van Beveren, E., Bonhommeau, S., Fromentin, J.-M., Bigot, J.-L., Bourdeix, J.-H., Brosset, P., Roos, D. \& Saraux, C. (2014) Rapid changes in growth, condition, size and age of small pelagic fish in the Mediterranean. Marine Biology, 161, 1809-1822.

Bonhommeau, S., Farrugio, H., Poisson, F. \& Fromentin, J.-M. (2010) Aerial surveys of bluefin tuna in the Western Mediterranean sea: retrospective, prospective, perspective. Collective Volume of Scientific Papers, 65, 801-811.

Brehmer, P., Guillard, J., Guennegan, Y., Bigot, J.L. \& Liorzou, B. (2006) Evidence of a variable 'unsampled' pelagic fish biomass in shallow water $(<20 \mathrm{~m})$ : the case of the Gulf of Lion. ICES Journal of Marine Science, 63, 444-451.

Ciancio, J.E., Pascual, M.A. \& Beauchamp, D.A. (2007) Energy Density of Patagonian Aquatic Organisms and Empirical Predictions Based on Water Content. Transactions of the American Fisheries Society, 136, 1415-1422.

Doray, M., Masse, J. \& Petitgas, P. (2010) Pelagic Fish Stock Assessment by Acoustic Methods at Ifremer. IFREMER, Sète, France.

Dubreuil, J. \& Petitgas, P. (2009) Energy density of anchovy Engraulis encrasicolus in the Bay of Biscay. Journal of Fish Biology, 74, 521-534.

Eder, E.B. \& Lewis, M.N. (2005) Proximate composition and energetic value of demersal and pelagic prey species from the SW Atlantic Ocean. Marine Ecology Progress Series, 291, 43-52.

Fromentin, J.-M., Bonhommeau, S. \& Brisset, B. (2013) Update of the index of abundance of juvenile bluefin tuna in the western Mediterranean sea until 2011. Collective Volume of Scientific Papers, 69, 454-461.

Fromentin, J.-M., Farrugio, H., Deflorio, M. \& De Metrio, G. (2003) Preliminary results of aerial surveys of bluefin tuna in the western Mediterranean sea. Collective Volume of Scientific Papers, 55, 10191027.

Harmelin, M.V., Mahe, K., Bodiguel, X. \& Mellon, C. (2012) Possible link between prey quality, condition and growth of juvenile hake (Merluccius merluccius) in the Gulf of Lions (NW Mediterranean). Cybium, 36, 323-328.

Hislop, J.R.G., Harris, M.P. \& Smith, J.G.M. (1991) Variation in the calorific value and total energy content of the lesser sandeel (Ammodytes marinus) and other fish preyed on by seabirds. Journal of Zoology, 224, 501-517.

Lawson, J.W., Magalhes, A.M. \& Miller, E.H. (1998) Important prey species of marine vertebrate predators in the northwest Atlantic: proximate composition and energy density. Marine Ecology Progress Series, 164, 13-20.

Montevecchi, W.A., Ricklefs, R.E., Kirkham, I.R. \& Gabaldon, D. (1984) Growth Energetics of Nestling Northern Gannets (Sula bassanus). The Auk, 101, 334-341. 
Plounevez, S. \& Champalbert, G. (2000) Diet, feeding behaviour and trophic activity of the anchovy (Engraulis encrasicolus L.) in the Gulf of Lions (Mediterranean Sea). Oceanologica Acta, 23, 175192.

Rosa, R., Gonzalez, L., Broitman, B.R., Garrido, S., Santos, A.M.P. \& Nunes, M.L. (2010) Bioenergetics of small pelagic fishes in upwelling systems: relationship between fish condition, coastal ecosystem dynamics and fisheries. Marine Ecology Progress Series, 410, 205-218.

Saraux, C., Fromentin, J.-M., Bigot, J.-L., Bourdeix, J.-H., Morfin, M., Roos, D., Van Beveren, E. \& Bez, N. (2014) Spatial Structure and Distribution of Small Pelagic Fish in the Northwestern Mediterranean Sea. PLoS ONE, 9, e111211.

Somers, I.F. (1988) On a seasonally oscillating growth function. Fishbyte, 6, 8-11.

Spitz, J. \& Jouma'a, J. (2013) Variability in energy density of forage fishes from the Bay of Biscay (northeast Atlantic Ocean): reliability of functional grouping based on prey quality. Journal of Fish Biology, 82, 2147-2152.

Tirelli, V., Borme, D., Tulli, F., Cigar, M., Fonda Umani, S. \& Brandt, S.B. (2006) Energy density of anchovy Engraulis encrasicolus L. in the Adriatic Sea. Journal of Fish Biology, 68, 982-989. 